\title{
Flow Separation in the Lee of a Crater Rim
}

\author{
Manuela Lehner ${ }^{1}$ D $\cdot$ C. David Whiteman ${ }^{2} \cdot$ Sebastian W. Hoch ${ }^{2} \cdot$ Bianca Adler $^{3}$. \\ Norbert Kalthoff ${ }^{3}$
}

Received: 16 January 2019 / Accepted: 4 July 2019 / Published online: 23 July 2019

(c) The Author(s) 2019

\begin{abstract}
The nearly circular Meteor Crater, Arizona, is located on an extensive, slightly sloping plain, above which a south-westerly katabatic flow forms during undisturbed, clear-sky nights. For the katabatic flow over the upstream crater rim, the resulting flow regime in the lee depends on the upstream wind speed. For a shallow katabatic flow with a wind-speed maximum of about $5 \mathrm{~m} \mathrm{~s}^{-1}$ or less at a height of about $20 \mathrm{~m}$ above the ground, the flow decelerates as it approaches the crater. Cold-air intrusions form, that is, cold air spills over the crater rim and runs down the inner south-west sidewall. For a deep katabatic flow with a wind-speed maximum located above the 50-m high measurement tower and comparatively higher wind speeds, the flow accelerates towards the crater. The flow separates in the immediate lee of the crater rim, forming a wake over the south-west crater sidewall. The wake can either be small, affecting only the upper part of the sidewall, or large, affecting the entire crater sidewall or even the crater floor. When flow separation occurs, the wake region over the crater sidewall is characterized by low wind speeds and potentially a return circulation near the surface. Particularly for large wakes, stability in the crater atmosphere is reduced and relatively high wind speeds occur at the crater floor, which is otherwise submerged in a strong surface-based inversion. Turbulent kinetic energy at the crater sidewall is typically higher during cold-air intrusions than is the case during flow separation, but high values can occur at the floor when a large wake forms.
\end{abstract}

Keywords Flow over topography $\cdot$ Lee vortex $\cdot$ METCRAX II $\cdot$ Wake formation

\section{Introduction}

As airflow interacts with topography, that is, as air is either forced to flow over mountains or depressions or to flow around them, the resulting flow regimes and processes depend strongly on flow characteristics (i.e., stability and speed) and on topographic characteristics

Manuela Lehner

manuela.lehner@uibk.ac.at

1 Department of Atmospheric and Cryospheric Sciences, University of Innsbruck, Innrain 52f, 6020 Innsbruck, Austria

2 Department of Atmospheric Sciences, University of Utah, Salt Lake City, UT, USA

3 Karlsruhe Institute of Technology, Karlsruhe, Germany 
(e.g., mountain height and width, lateral extension, slope angle, and surface roughness) (e.g., Vosper 2004; Jackson et al. 2012; Lehner et al. 2016a; Rotunno and Lehner 2016). For airflow around obstacles, vertical-axis vortices can form in the lee (e.g., Smolarkiewicz and Rotunno 1989; Katurji et al. 2013), with the resulting wake region in the lee typically characterized by reduced mean wind speeds and high turbulence intensity (Katurji et al. 2013). Lee vortices with a horizontal axis, on the other hand, form as air flows over obstacles and separates from the surface in the lee, resulting, for example, in turbulent rotors (e.g., Doyle and Durran 2007) or recirculation zones in the immediate lee of the mountain (e.g., Gerber et al. 2017; Menke et al. 2018).

Boundary-layer or flow separation in the lee of obstacles occurs due to the presence of an adverse pressure gradient that causes a deceleration of the flow, particularly in the nearsurface layer (e.g., Scorer 1955; Wood 1995; Belcher and Hunt 1998; Ambaum and Marshall 2005). Baines (1995) defines three different boundary-layer-separation regimes based on laboratory experiments: (i) boundary-layer separation at the mountain crest (i.e., bluff-body flow separation), (ii) flow separation farther down the lee sidewall below the first wave crest, which he calls post-wave separation, and (iii) complete attachment, that is, no separation occurs. The three flow types are characterized by their location in a regime diagram as a function of $H / W$ and $N H / U$, where $H$ is the mountain height, $W$ is the length of the lee slope, $N$ is the Brunt-Väisälä frequency, and $U$ is the upstream wind speed. The formation of bluff-body flow separation depends on the ratio between the wavelength of the internal waves $2 \pi U / N$ and $W$ so that boundary-layer separation occurs if $N W / U<\pi$. Post-wave separation, on the other hand, occurs when $N H / U$ is above a critical threshold value.

Ambaum and Marshall (2005) derived a vorticity equation to describe accelerations and decelerations for flow over a hill. They assumed that flow separation occurs if the decrease in flow speed is large enough, that is, of the same order of magnitude as the unperturbed base-state velocity. For small aspect ratios (i.e., for hills with low heights compared to their half width) linear solutions to their equation reproduced the regime diagram of Baines (1995). According to their solutions, the location of flow deceleration and thus flow separation depends on the flow solution, that is, whether the solution is evanescent or wave-like, that is, whether waves decay with height or not. For evanescent solutions, deceleration occurs along the lee slope of the hill and flow separation in the immediate lee of the hill is thus possible if flow deceleration is large enough. For wave-like solutions, deceleration starts farther downstream over the lee slope of the hill. If flow separation occurs, it will thus be in the form of post-wave separation.

Post-wave separation is closely related to rotor formation in the lee of mountains. Rotors form when the boundary layer separates from the surface because of adverse horizontal pressure gradients that occur in connection with trapped lee waves (Doyle and Durran 2002, 2007; Vosper 2004). With the horizontal wind speed increasing with height close to the surface due to surface friction, vertical wind shear produces a thin layer of positive vorticity in the direction parallel to the obstacle, which is lifted into the wave. Hertenstein and Kuettner (2005) identified a second type of rotor based on numerical simulations, which is reminiscent of a hydraulic jump and that results from negative vorticity parallel to the obstacle being produced by the baroclinicity in connection with the deformation of an inversion layer. The two types of rotors have also been observed experimentally in the lee of the Medicine Bow Mountains, Wyoming, by French et al. (2015).

Idealized simulations with a two-layer atmosphere by Vosper (2004) showed that if the Froude number $F=U / \sqrt{g^{\prime} z_{i}}$ is within a certain range that allows the formation of trapped lee waves, and if $H / z_{i} \geq 0.3$, the wave amplitude becomes large enough to cause rotor formation, where $z_{i}$ is the depth of the lower layer and $g^{\prime}=g \Delta \theta / \theta_{0}$ is the reduced acceleration due 
to gravity, with $g$ the acceleration due to gravity, $\Delta \theta$ the potential temperature difference across the temperature inversion separating the lower from the upper layer and $\theta_{0}$ is the reference potential temperature in the lower layer. Doyle and Durran (2002) defined a nondimensional pressure-gradient threshold criterion for post-wave flow separation based on idealized simulations. Applying this criterion to observations in the lee of the Medicine Bow Mountains, Wyoming, Strauss et al. (2016) found, however, that flow separation occurs for even smaller pressure gradients. They suggest that, in addition to pressure-gradient forces, buoyancy forces may contribute to flow deceleration and thus boundary-layer separation.

Bluff-body flow separation in the lee of obstacles has been shown to occur in water tank studies (e.g., Baines and Hoinka 1985), and occasional observations in the atmosphere have been reported, for example, in the lee of the Sierra Nevada by Grubišić and Doyle (2006). Lidar observations described by Gerber et al. (2017) showed recirculation in the lee of the Sattelhorn Ridge in the Dischma Valley, Switzerland, which persisted for more than $16 \mathrm{~h}$ with a horizontal extent of 400-1000 m and a vertical extent of up to about $200 \mathrm{~m}$. Indirect observations of flow separation have also been reported. Strauss et al. (2015) observed high turbulence intensities in the immediate lee of the Medicine Bow Mountains suggesting the presence of bluff-body flow separation. A visualization of horizontal-axis lee vortices occurs when clouds form and vortices in the immediate lee of mountain peaks have been identified as the most likely formation mechanism for so-called banner clouds (Wirth et al. 2012; Voigt and Wirth 2013).

As indicated by Baines (1995), the occurrence of bluff-body flow separation in the lee of an obstacle depends on the speed of the approaching flow and on the stability. Mason (1987) observed flow separation or decoupling in a small, approximately 200-m deep valley under neutral and unstable conditions, while the flow remained attached under stable conditions with a Froude number $<2$, and was able to reproduce that result with numerical simulations. Similar results based on tethersonde measurements were found by Holden et al. (2000). They showed that a decoupling of the flow was favoured under relatively high gradient Richardson numbers. Idealized simulations of flow over small basins by Lehner et al. (2016a) produced flow separation over the upstream basin edge for the highest wind speeds $\left(15 \mathrm{~m} \mathrm{~s}^{-1}\right)$ and with the deepest basins (100 and $150 \mathrm{~m}$ ). Menke et al. (2018) probed a recirculation zone in the lee of two parallel mountain ridges in central Portugal at three different cross-sections with six scanning Doppler lidars and found that reversed flow with wind speeds $>0.5 \mathrm{~m} \mathrm{~s}^{-1}$ occured $50 \%$ of the time and that the occurrence of the recirculation zone depended on stability (specifically, most frequent occurrence for near-neutral and unstable conditions), on wind speed (most frequent occurrence for wind speeds $>8 \mathrm{~m} \mathrm{~s}^{-1}$ ), and on the topography, that is, they observed variations among the three different cross-sections.

Flow separation also strongly depends on the topography, for example, the sharpness of the mountain top or ridge line, with separation being more likely in the presence of salient edges (Scorer 1955; Batchelor 1967; Kim et al. 2001). Flow separation and the formation of a recirculation zone in the lee is also facilitated by steeper slopes (Arya et al. 1987; Kim et al. 2001; Wood 1995) and by denser canopies, that is, higher surface roughness (Wood 1995; Poggi and Katul 2007; Patton and Katul 2009). Wood (1995), for example, estimated the critical slope angle for flow separation based on idealized simulations, finding a lower critical slope angle for higher surface roughness. They also showed that, for $2 \mathrm{D}$ cases, the separation point moves upstream with increasing hill height and that the recirculation eddy size increases.

In this paper we present night-time observations of flow separation at the rim of Arizona's Meteor Crater during comparatively high-wind-speed periods. The wake that forms over the south-west crater sidewall is characterized by low wind speeds and sometimes a return flow 
near the surface, that is, an upslope flow component. Flow separation and wakes are usually difficult to observe because they form in the immediate lee (i.e., along the upper sidewalls) of obstacles, which are oftentimes not easily accessible and therefore not instrumented and may be beyond the range of surface-based remote sensing instrumentation, so that most of the work on flow separation is based on laboratory experiments and numerical simulations. The small size of the Meteor Crater and its instrumentation during the Meteor Crater Experiment II (METCRAX II; Lehner et al. 2016b) field campaign, however, proved almost ideal to identify and investigate flow separation. The physical characteristics of the Meteor Crater and the dataset are described in Sect. 2 and evidence for flow separation in the lee of the crater rim is presented in Sect. 3.

While relatively few direct observations of flow separation in the atmosphere have been reported so far, observations such as those by Menke et al. (2018) suggest, however, that flow separation may be a frequent phenomenon at certain locations. This is also true for the observations from the Meteor Crater, at which location flow separation occurs frequently during night-time periods. The paucity of observations from the atmosphere also means that knowledge of atmospheric conditions leading to flow separation is limited. One goal herein is thus to use the one-month long continuous measurements at Meteor Crater and compare periods with and without flow separation to identify the upstream flow conditions leading to flow separation and wake formation. These results are compared to the flow-separation criterion by Baines and Hoinka (1985), which is based on laboratory experiments, to show that the criterion is useful in identifying flow separation in the atmosphere.

The formation of a wake in connection with flow separation with a modified mean and turbulent flow field has potential impacts on air pollution dispersion in mountain valleys or the siting of wind turbines. Our goal is thus to characterize the mean flow and turbulence conditions within the wake region and the effect of the wake flow on the downstream crater atmosphere. The atmospheric conditions leading to flow separation and the characteristics of the flow in the resulting wake region are described in Sects. 4 and 5, respectively. Finally, a brief summary and conclusions are given in Sect. 6 .

\section{Data and Methods}

\subsection{The Nocturnal Atmosphere in the Meteor Crater}

The Meteor Crater in northern Arizona $\left(35^{\circ} \mathrm{N}, 111^{\circ} \mathrm{W}\right)$ is a nearly circular, bowl-shaped basin that was produced by a meteorite impact 49,000 yr ago (Fig. 1). It is about $1.2 \mathrm{~km}$ in diameter, $170 \mathrm{~m}$ in depth, and is surrounded by a rim that extends $30-50 \mathrm{~m}$ above the surrounding plain, which rises slightly to the south-west with a slope angle of about $1^{\circ}$. Two major field campaigns, the Meteor Crater Experiment (METCRAX; Whiteman et al. 2008) and METCRAX II (Lehner et al. 2016b), were performed to study various aspects of the crater meteorology. The focus of METCRAX II in October 2013 was on the flow past the crater basin. During clear-sky, quiescent nights, a surface-based inversion and a southwesterly katabatic flow form over the plain surrounding the Meteor Crater, with a typical inversion depth and strength of about $50 \mathrm{~m}$ and $0.15 \mathrm{~K} \mathrm{~m}^{-1}$, respectively, and a wind-speed maximum of $5 \mathrm{~m} \mathrm{~s}^{-1}$ at $30 \mathrm{~m}$ above ground level (a.g.l.; Whiteman et al. 2018a). Once the depth of the inversion exceeds the height of the crater rim, the cold air drains into the crater over the upwind, south-west rim until air parcels reach their level of neutral buoyancy (Whiteman et al. 2018a). This inflow of cold air modifies the nocturnal stratification within the crater, resulting in a shallow and strong surface-based inversion above the crater floor, 


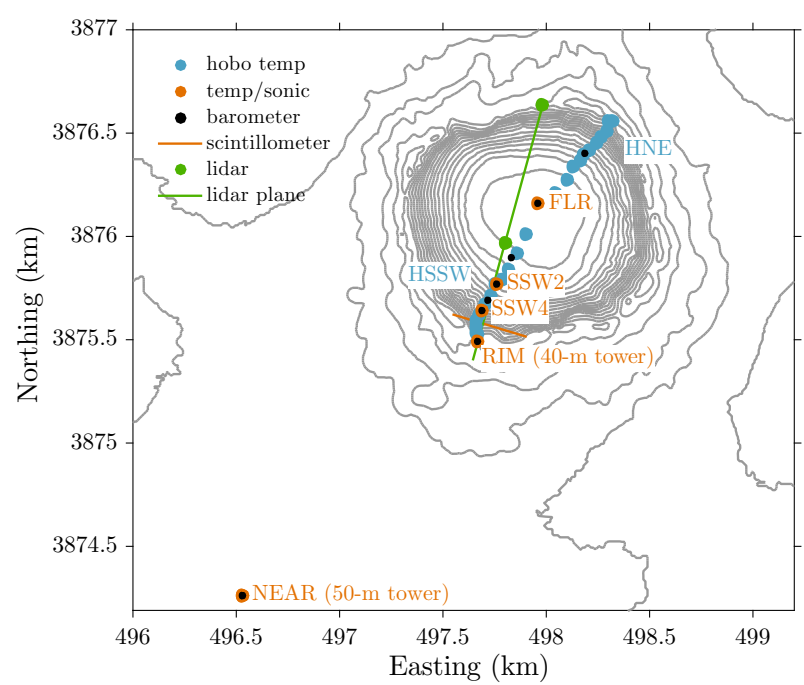

Fig. 1 Topography of the Meteor Crater with the location of the measurement sites used in this study. The orange and green lines indicate the scintillometer path and the Dual-Doppler lidar plane, respectively. Elevation contour lines are at 10 -m intervals

which is topped by a deep near-isothermal layer and a capping inversion near the top of the crater (Whiteman et al. 2010; Haiden et al. 2011). With a deepening of the katabatic flow upstream and an increase in wind speed, the flow over the crater topography also leads to the formation of a wave over the basin because of shear instability, which can reach amplitudes exceeding the crater depth (Adler et al. 2012; Whiteman et al. 2018b).

\subsection{Data}

The data used in this study are from the METCRAX II experiment. A detailed description of the METCRAX II field campaign, the measurement sites, and the instrumentation can be found in Lehner et al. (2016b). The measurement sites are shown in Fig. 1 and Table 1 lists further details about the instrumentation. The data are from two lines of temperature data-loggers (HOBO, Onset Computer, Inc., Bourne, Massachusetts), which ran up the northeast and south-south-west crater sidewalls (labeled HNE and HSSW in Fig. 1), with eleven and twelve sensors, respectively. The sensors were installed in solar radiation shields at $1.2 \mathrm{~m}$ a.g.l., with instantaneous temperature values recorded every $2.5 \mathrm{~min}$. A 40-m high tower was installed at the crater rim (RIM), which was instrumented with CSAT3 sonic anemometers (Campbell Scientific, Logan, Utah) and hygrothermometers (National Center for Atmospheric Research (NCAR), Boulder, Colorado) measuring temperature and relative humidity at 5-m intervals. A similarly instrumented 50-m high tower was installed about $1.6 \mathrm{~km}$ upstream and south-west of the Meteor Crater (NEAR), with the lowest measurement level at $3 \mathrm{~m}$ instead of $5 \mathrm{~m}$ to be used as part of a full surface-energy-balance station. Additional sonic anemometers were installed at $3 \mathrm{~m}$ a.g.l. at two sites along the south-south-west crater sidewall, approximately 40 (SSW2) and $90 \mathrm{~m}$ (SSW4) above the crater floor, and at the crater floor itself (FLR). Wind data from the sonic anemometers were tilt corrected (Wilczak et al. 2001) and turbulence statistics were calculated for 5-min averaging intervals from the 20-Hz measurements, a common averaging length for stable night-time measurements (e.g., 


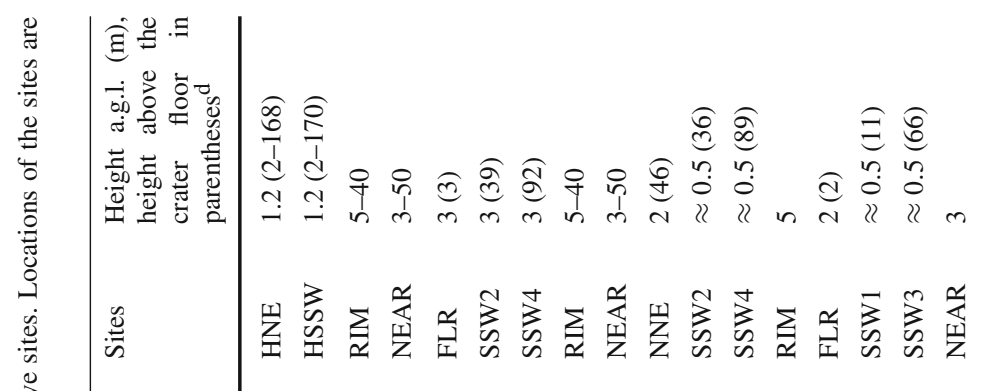
常

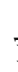

. 
Mahrt et al. 1998; van de Wiel et al. 2003) and which allows the analysis of relatively fastchanging conditions in the atmosphere. Unless noted otherwise, all data shown hereafter are 5-min averaged values. For the analysis of turbulence characteristics in Sect. 5, wind-velocity variances and covariances containing horizontal wind-velocity components were rotated into a streamwise coordinate system, using the 5-min averaged wind direction. Further data are from a network of barometers in the crater, a combination of PTB220 barometers (Vaisala, Helsinki, Finland) and nanobarometers (Paroscientific, Inc., Redmond, Washington), with a resolution of $0.1 \mathrm{~Pa}$ and $0.01 \mathrm{~Pa}$, respectively. Barometers were installed at the FLR, SSW2, and SSW4 sites, a site located in-between the SSW2 and SSW4 sites (SSW3, about $65 \mathrm{~m}$ above the crater floor), and a site downslope from the SSW2 site (SSW1, about $10 \mathrm{~m}$ above the crater floor). Hydrostatic pressure was sampled with a frequency of $1 \mathrm{~Hz}$ and averaged over 5-min intervals for the analysis. Pressure measurements from the south-west sidewall are analyzed with respect to data from a nanobarometer on the relatively undisturbed northeast sidewall (NNE, $45 \mathrm{~m}$ above the crater floor). The SSW1, SSW3, and NNE sites are not labeled in Fig. 1. Turbulence measurements in the immediate lee of the south-west crater rim were made with a surface-layer scintillometer (SLS20, Scintec AG, Rottenburg, Germany). Two scanning Doppler lidars were operated at the crater floor (Streamline, Halo Photonics, United Kingdom) and at the north crater rim (WindCube, Leosphere, France). Data from co-planar range-height indicator (RHI) scans were used to derive the two-dimensional wind fields in the scanning plane (green line in Fig. 1).

Data are analyzed for the period 4-29 October, when all of these instruments were operational. The analysis is restricted to night-time periods between 1800 and 0600 MST (Mountain Standard Time $=$ UTC $-7 \mathrm{~h}$ ) and to periods when, (i) an inversion was observed at the NEAR tower between the top and the bottom levels of the tower $\left(T_{50 m}-T_{3 m}>0\right)$ and (ii) the wind direction at $50 \mathrm{~m}$ a.g.l. at the NEAR tower was from a southerly to south-westerly direction $\left(165-255^{\circ}\right)$ to indicate a katabatic flow. These criteria had to be met for at least one continuous hour based on 5-min averaged data values for the data to be included in the analysis. Approximately $46 \%$ of the 3625 5-min night-time data samples between 4 and 29 October (25 nights times 12 hours) were thus available for the analysis.

\section{Flow Separation in the Meteor Crater}

An analysis of the cold-air intrusions coming over the south-west crater rim during Intensive Observational Period (IOP) 7 (26-27 October) showed temporal increases in wind speed along the south-west sidewall in connection with changes in the level of neutral buoyancy of the cold air flowing over the crater rim (Whiteman et al. 2018a). Specifically, the SSW2 site in the lower part of the sidewall (see Fig. 1) is located close to the top of the shallow (30-40 m) and strong (5-10 K potential temperature change) crater-floor inversion, with wind speeds close to zero when unaffected by the intrusions. When the level of neutral buoyancy of the cold air flowing down the crater sidewall descends below the SSW2 site, an increase in wind speed to about $3-5 \mathrm{~m} \mathrm{~s}^{-1}$ is observed at the SSW2 site.

Plotting the wind speed along the south-west sidewall, at the SSW4 and SSW2 sites, against the wind speed averaged over the 40-m deep layer sampled at the crater rim for the entire month, however, reveals the presence of two different flow regimes (Fig. 2). The first or intrusion regime is characterized by relatively low wind speeds of less than about $5 \mathrm{~m} \mathrm{~s}^{-1}$ at the RIM tower and along the sidewall. Wind speeds at the lower inner sidewall (SSW2) show a near-linear increase with respect to the wind speed at the RIM tower. In the second or separation regime, RIM-tower wind speeds of $5 \mathrm{~m} \mathrm{~s}^{-1}$ or more coincide with low wind speeds 

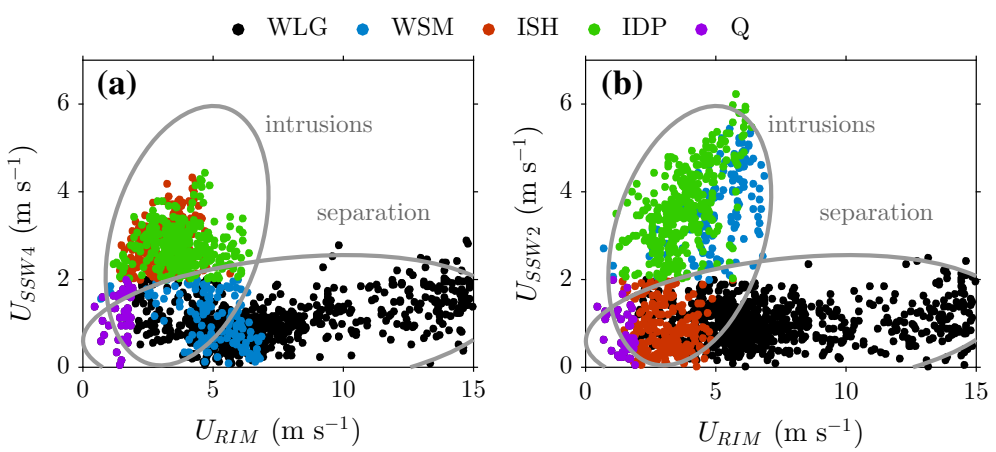

Fig. 2 Wind speed at the, a SSW4, and b SSW2 sites as a function of the mean wind speed at the RIM tower. The five colour-coded regimes are indicated in the legend at the top of the figure and explained in Sect. 4

along the sidewall. Wind speeds at the sidewall show no dependence on the wind speed at the RIM tower. This suggests the formation of a wake above the sidewall as a result of flow separation in the lee of the crater rim. When wind speeds exceed about $7 \mathrm{~m} \mathrm{~s}^{-1}$ at the rim, only the flow-separation regime seems to occur. For wind speeds lower than about $7 \mathrm{~m} \mathrm{~s}^{-1}$, however, either low or high wind speeds are observed along the sidewall. For very low wind speeds it is of course difficult to distinguish between the two regimes based on the wind speed along the south-west sidewall, because even for the intrusion regime only low wind speeds are expected to occur. Results similar to Fig. 2 are obtained if the mean wind speed at the RIM tower is replaced with the maximum wind speed over the eight vertical levels, or with the values at the bottom and top of the 40-m tower. The five categories indicated by different colours in Fig. 2 and in the background of Fig. 3 will be discussed in Sect. 4.

Figure 3a-c shows an example of a cold-air-intrusion dominated night (26-27 October; IOP 7), the same night that was analyzed by Whiteman et al. (2018a). Wind speeds at the SSW4 site are similar to wind speeds at $5 \mathrm{~m}$ a.g.l. at the RIM tower and the wind direction is from the south-west, indicating a flow down the slope (Fig. 3a, b). Wind speeds, and to a lesser degree wind directions, are more variable at the SSW2 site, showing strong increases and decreases in wind speed, which indicate whether the cold-air intrusion penetrates below the SSW2 site or whether it reaches its level of neutral buoyancy already above the SSW2 site (Whiteman et al. 2018a). An example of a deep intrusion is visible in Fig. 4a, which shows the Dual Doppler retrieval of the wind field within the lidar-scan plane at 0355 MST. The layer of cold-air intrusions along the south-west sidewall is relatively shallow, with a depth of about $50 \mathrm{~m}$, and is thus just barely captured by the Dual Doppler retrieval (Fig 4a), but better resolved in the radial-velocity field of the individual RHI scans from the FLR lidar (not shown).

A strong inversion is present in the lowest layer of the crater atmosphere, with the potential temperature near the crater floor $5-10^{\circ} \mathrm{C}$ lower than at the crater rim or in the upper part of the north-east sidewall (Fig. 3c). Whiteman et al. (2018a) have shown that the temperature measurements along the north-east sidewall are representative of the vertical temperature structure in the quiescent nocturnal crater atmosphere when disturbances are restricted to a shallow cold-air-intrusion layer over the south-west sidewall. Wind speeds at the crater floor at the bottom of the inversion are small and wind direction is correspondingly variable.

During the night of 16-17 October (IOP 3; Fig. 3d-f), flow separation occurred over the south-west sidewall. Wind speeds at the SSW4 site are comparatively low, typically below $2 \mathrm{~m} \mathrm{~s}^{-1}$, and generally decrease at the same time as wind speeds increase at the RIM tower 

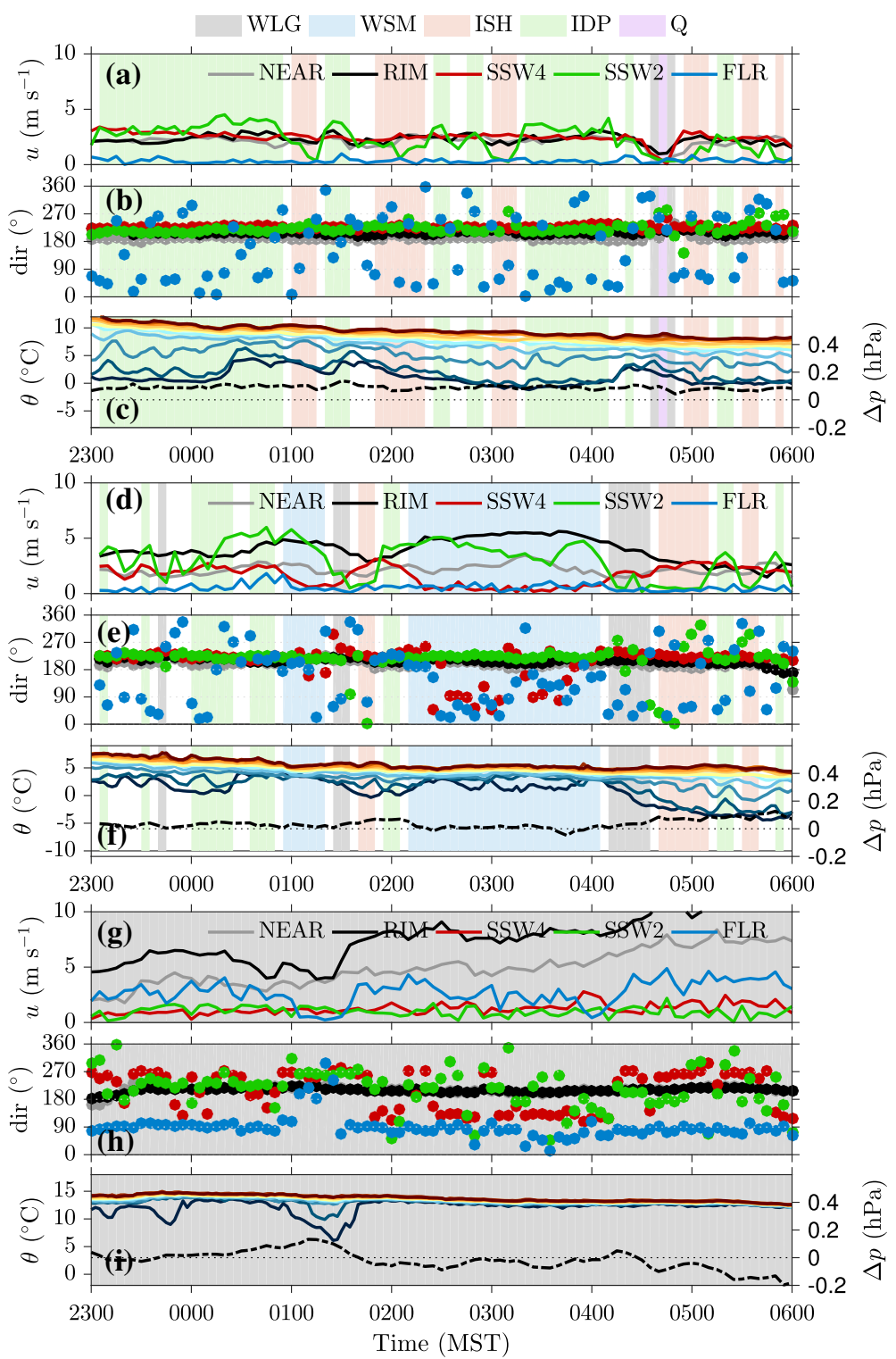

Fig. 3 Time series of $\mathbf{a}, \mathbf{d}, \mathbf{g}$ wind speed and $\mathbf{b}, \mathbf{e}, \mathbf{h}$ wind direction at the NEAR tower ( $3 \mathrm{~m}$ a.g.1.), the RIM tower (5 $\mathrm{m}$ a.g.1.), and the SSW4, SSW2, and FLR sites; c, f, i potential temperature (left axes) at different sites running up the north-east sidewall from the crater floor (dark blue) to the rim (dark red) at approximately 10-20 m height intervals and pressure difference between the RIM tower and the NEAR tower (right axes; dashed line) on a-c 26-27, d-f 16-17, and g-i 27-28 October. Data from the temperature data-loggers are 2.5-min instantaneous values. The line colours for the different sites are identical for wind speed $\mathbf{a}, \mathbf{d}, \mathbf{g}$ and wind direction $\mathbf{b}, \mathbf{e}, \mathbf{h}$. The colour shading indicates the flow regimes (legend at the figure top) as explained in Sect. 4

and vice versa (Fig. 3d). For example, around $0030 \mathrm{MST}$, the wind speed starts to increase at the RIM tower and about $15 \mathrm{~min}$ later it decreases at the SSW4 site. Around $0200 \mathrm{MST}$, the opposite occurs and the two wind speeds become almost identical for a short period of 

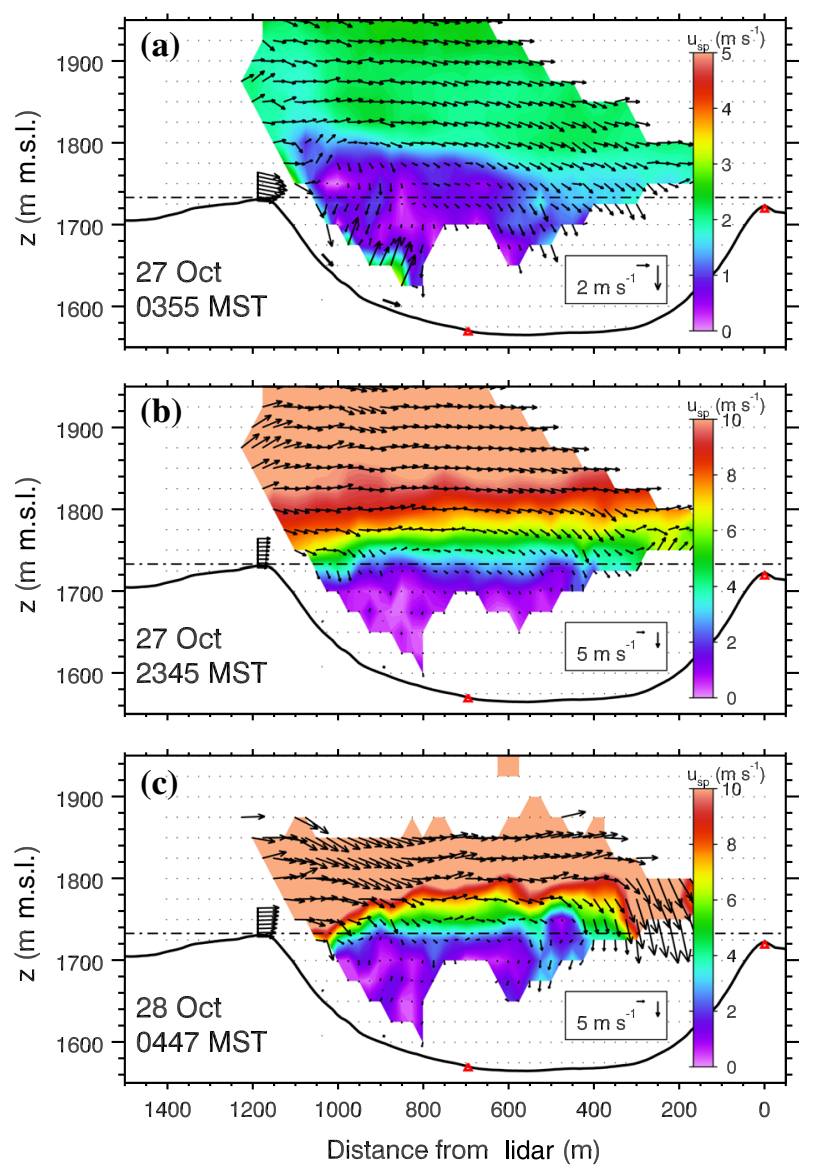

Fig. 4 5-min averaged fields of the wind-velocity component in the approximately south-west to north oriented lidar-scan plane $\left(u_{s p}\right)$ through the crater (green line in Fig. 1) from Dual-Doppler lidar measurements at, a 0355 MST 27 October, b 2345 MST 27 October, and c 0447 MST 28 October. The wind arrows at the southwest crater rim and along the south-west sidewall are from the RIM tower and the sonic anemometers at the SSW4 and SSW2 sites, respectively. Red triangles indicate lidar locations

time, before the wind speed increases again at the RIM tower and drops to almost zero at the SSW4 site. This regime then lasts for almost two hours until about 0400 MST. The wind direction during this period of near-calm conditions turns mostly to a north-easterly upslope direction, indicating a return circulation within the wake region (Fig. 3e). A persistent return circulation, however, does not form during all other flow-separation periods, which could be related to the fact that there is always forcing for a thermally-driven downslope flow opposing the return circulation due to local surface cooling along the sidewall. It is thus conceivable that the forcing for downslope flows can exceed the forcing for the return flow so that downslope flows are observed near the surface instead of the return flow. Alternatively, the flow might turn to an upslope direction intermittently, which is not resolved by the 5-min averages, or shallow thermally-driven downslope flows might form underneath the return flow, which, however, cannot be verified with the present dataset.

In contrast to the SSW4 site, wind speeds at the SSW2 site are generally high during this night, with flow from a south-westerly, downslope direction, suggesting that the flow 
reattaches to the surface downstream of the wake. Near-calm conditions at the FLR site are again consistent with a decoupling of the lowest basin atmosphere, although the stability is generally weaker during this night (Fig. 3f) than during the intrusion-dominated night of 2627 October (Fig. 3c). Particularly during the two flow-separation periods around 0100 MST and between 0200 and 0400 MST, the potential temperature near the crater floor is only slightly lower than in the upper part of the crater, indicating a well-mixed crater atmosphere. During the short break around 0200 MST and after 0400 MST, the temperature in the lower part of the crater decreases, leading to the formation of a new crater-floor inversion.

While the wake during the night of 16-17 October extends only to the SSW4 site but not to the SSW2 site, where relatively high wind speeds are observed, larger wakes also form that extend farther down the south-west sidewall. An example is shown in Fig. $3 \mathrm{~g}-\mathrm{i}$ for the night of 27-28 October. Wind speeds along the south-west sidewall are generally low, both at the SSW4 site and the SSW2 site, while wind speeds at the RIM tower exceed $5 \mathrm{~m} \mathrm{~s}^{-1}$ (Fig. 3g). Wind speeds at the FLR site are also higher than over the sidewall and the wind direction is consistently from the north-east (Fig. 3h), that is, opposing the southwesterly flow over the crater, suggesting the formation of a large crater-sized eddy. This is consistent with a well-mixed crater atmosphere, with a brief exception between 0100 and 0200 MST, when a shallow, about $5 \mathrm{~m}$-deep, layer cools above the crater floor (Fig. 3i). This short period coincides with slightly reduced wind speed at the RIM tower and near-calm conditions at the FLR site (Fig. 3g). Flow separation at the crater rim is also visible in the lidar wind fields (Fig. 4b,c). Figure 4c indicates strong subsidence near the downwind crater sidewall, consistent with the occurrence of a large eddy. Most of the lidar data during this night, however, show flow over the crater top similar to Fig. 4b, although the region near the north-east sidewall is not captured well by the co-planar lidar scans.

\section{Conditions for Flow Separation}

Figure 2 showed that the wind speed within the wake region is generally less than about $2 \mathrm{~m} \mathrm{~s}^{-1}$. Here, the wake region is defined relatively loosely as the region with comparatively low wind speeds. Since there were only two sites with wind measurements along the southwest sidewall, the area of the wake cannot be defined precisely. We can, however, use the wind information to identify wake occurrences objectively for further analysis. Because Fig. 2 also shows individual wake events with slightly higher wind speeds than $2 \mathrm{~m} \mathrm{~s}^{-1}$ when the wind speed at the rim is very high, times with wind speeds exceeding $7 \mathrm{~m} \mathrm{~s}^{-1}$ at the rim are also classified as wakes independent of the wind speed at the SSW2 and SSW4 sites. Based on this classification scheme, and on the information provided by the examples in Fig. 3, we define five different categories: (i) A large wake or complete decoupling of the crater atmosphere similar to the night of 27-28 October (Fig. $3 \mathrm{~g}-\mathrm{i}$ ) is defined when the wind speed at the RIM tower is larger than $7 \mathrm{~m} \mathrm{~s}^{-1}$ or when the wind speeds at both the SSW2 and the SSW4 sites are below $2 \mathrm{~m} \mathrm{~s}^{-1}$ (WLG-large wake). (ii) A small wake that affects only the upper part of the south-west sidewall similar to the night of 16-17 October (Fig. 3d-f) is defined when the wind speed at the RIM tower is less than $7 \mathrm{~m} \mathrm{~s}^{-1}$ and the wind speed at the SSW4 site is below $2 \mathrm{~m} \mathrm{~s}^{-1}$, but the wind speed farther down the slope at the SSW2 site is larger than $2 \mathrm{~m} \mathrm{~s}^{-1}$ (WSM-small wake). (iii) A cold-air intrusion that does not extend to the SSW2 site similar to the period shortly after 0300 MST during the night of 26-27 October (Fig. 3a-c) is defined when the wind speed is higher than $2 \mathrm{~m} \mathrm{~s}^{-1}$ at the SSW4 site but lower than $2 \mathrm{~m} \mathrm{~s}^{-1}$ at the SSW2 site (ISH-shallow intrusion). (iv) A cold-air intrusion that reaches beyond the SSW4 site similar to, for example, the period after about 0315 MST during the night of 

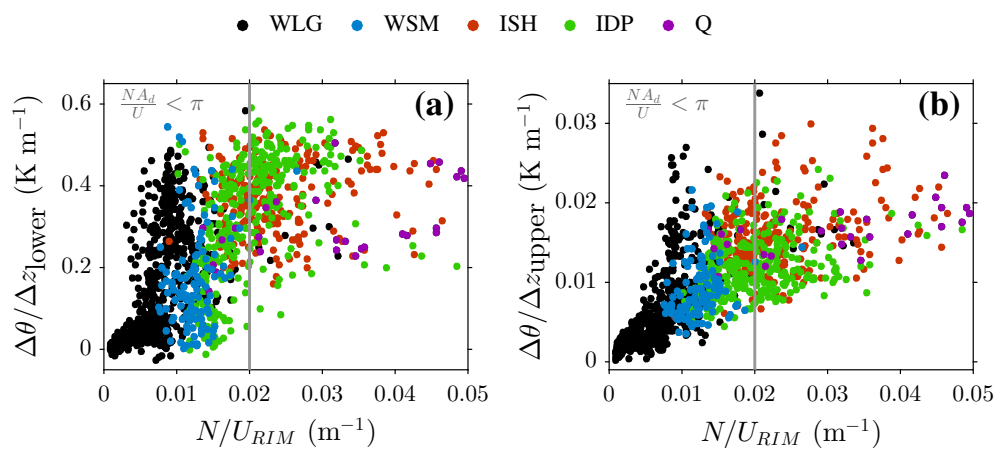

Fig. 5 Pseudo-vertical potential-temperature gradients across $\mathbf{a}$ the lower $25 \mathrm{~m}$ and $\mathbf{b}$ the top $91 \mathrm{~m}$ as a function of $N / U$ at the RIM tower. Potential-temperature gradients were calculated from temperature sensors on the north-east sidewall and $N$ and $U$ were averaged over the 40-m tower. Data from the temperature sensors are instantaneous values in the centre of the 5-min averaged values of $N$ and $U$. The criterion for flow separation by Baines (1995) is indicated by a vertical grey line. Note the different ranges of the potential-temperature gradient in the two frames

26-27 October (Fig. 3a-c) is defined when the wind speeds at both the SSW2 and the SSW4 sites exceed $2 \mathrm{~m} \mathrm{~s}^{-1}$ (IDP-deep intrusion). (v) Finally, a quiescent category is defined for those cases when the wind speeds at the RIM tower and at both the SSW4 and the SSW2 sites are less than $2 \mathrm{~m} \mathrm{~s}^{-1}$ ( $\mathrm{Q}$ - quiescent), which are not likely to be wake cases in spite of the low wind speeds over the south-west sidewall. These five regimes are colour-coded hereafter and added as background colours in the time series of the three case studies, similar to Figs. 2 and 3. The background colours in Fig. 3 thus indicate, for example, an approximately 2-h long small wake around $0300 \mathrm{MST}$ on 16-17 October (Fig. 3d-f) and the presence of a large wake during the entire night of 27-28 October (Fig. 3g-i).

The criterion for lee-side flow separation defined by Baines (1995) states that the halfwidth of the obstacle in the lee has to be smaller than the half wavelength of the internal waves excited by the obstacle, that is, $N A_{d} / U<\pi$, where $A_{d}$ is the half-width of the obstacle. The inner crater sidewall has an approximate length of $300 \mathrm{~m}$, and using a half-width of $150 \mathrm{~m}$ gives $N / U=\pi / 150 \approx 0.02 \mathrm{~m}^{-1}$. Figure 5 shows scatter plots of the stability in the crater, that is, the vertical potential-temperature difference across fixed layers, as a function of $N / U$ at the RIM tower, where $N$ was calculated layer-wise between consecutive height levels of the 40-m high tower and then averaged over all layers. Calculating $N$ as a bulk measure between the top and the bottom level of the tower gives essentially the same results (not shown). Wind speed $U$ is also averaged over all vertical levels. Potential-temperature gradients in the crater are pseudo-vertical gradients, that is, they were calculated from the near-surface temperature measurements along the north-east sidewall. The data show a regime transition around $0.015 \mathrm{~m}^{-1}$, with flow separation occurring for $N / U \lesssim 0.015 \mathrm{~m}^{-1}$, that is, slightly below the criterion defined by Baines (1995). It has to be kept in mind, however, that the Brunt-Väisälä frequency and the wind speed vary with height and that the mean values are thus only approximations, as is the estimate of $A_{d}$. Small wakes, which affect only the SSW4 site, occur at the upper end of this range between about 0.007 and $0.015 \mathrm{~m}^{-1}$.

The criterion by Baines (1995) contains the stability upstream or at the crater rim. Strauss et al. (2016), however, suggested that the stability in the valley downstream may also facilitate or prevent flow separation. Although their argument was made for post-wave separation and rotor formation, it is also considered here for bluff-body separation. The nocturnal atmosphere in the Meteor Crater is typically characterized by a strong and shallow inversion at the crater 
floor, with a close to isothermal layer above (Whiteman et al. 2010, 2018b). Figure 5 shows the pseudo-vertical potential-temperature gradients within the crater-floor inversion (i.e., across the lowest 25-m deep layer) and within the near-isothermal layer (i.e., across the top 91-m deep layer). The potential-temperature gradients were calculated from four temperature sensors on the north-east sidewall, which best represents ambient conditions within the crater. As already seen for the three case studies presented in Fig. 3, the stability in the lower part of the crater is much higher during intrusions than during flow separation. Particularly for large wakes, the crater atmosphere is oftentimes close to neutral throughout its entire depth. This is likely a result of increased wind speeds and thus mixing in the crater during this flow regime. Figure 5a, however, also shows that large wakes can also be accompanied by a relatively strong stability in the lowest layer. Small wakes, which only affect the upper part of the south-west crater sidewall, however, are not likely to lead to a mixing of the entire crater themselves. Figure 5b shows that their occurrence is usually also accompanied by lower stabilities compared to intrusions, also in the upper, near-isothermal layer, which may thus facilitate flow separation.

Stiperski et al. (2018) analyzed vertical profiles upwind of the crater at the NEAR tower and distinguished two different types of katabatic flows approaching the crater. A shallow type with a wind-speed maximum at 15-25 $\mathrm{m}$ a.g.l. and a deeper type with the wind-speed maximum near the top of the 50-m tower. The latter is also characterized by weaker directional wind shear with height and weaker near-surface stratification. These differences in the katabatic flow profiles have different effects on the crater atmosphere. While nearly continuous cold-air intrusions over the south-west rim into the crater basin occur during shallow katabatic-flow periods (Whiteman et al. 2018a), large-amplitude waves form over the basin with increased flow speeds along the south-west sidewall during deep katabatic flows (Adler et al. 2012; Whiteman et al. 2018b). Figure 6 shows wind-speed and stability profiles at the NEAR and RIM towers for the five different flow categories. Both intrusion categories and also the quiescent conditions are characterized by a distinct jet profile. The wind profiles show a wind-speed maximum of about $5 \mathrm{~m} \mathrm{~s}^{-1}$ around $25 \mathrm{~m}$ a.g.l. at the NEAR tower and a stability maximum at about $15 \mathrm{~m}$ a.g.l. for both intrusion regimes. This agrees with Whiteman et al. (2018a) that flow intrusions occur with a shallow katabatic flow. The wind-speed and stability profiles for the wake cases agree better with the deep katabatic flow described by Stiperski et al. (2018), with a continuous increase in wind speed throughout the height of the 50-m tower and comparatively lower stability. For the large wakes, the 90th percentiles show that cases with much higher wind speeds are possible. The conditions for flow separation thus match the conditions for the formation of deep waves and warm-air intrusions over the crater described by Whiteman et al. (2018b).

The wind profiles in Fig. 6 show another distinct difference between flow-intrusion and flow-separation regimes. For flow intrusions and quiescent conditions, near-surface wind speeds at the NEAR tower and at the RIM tower are very similar. Above approximately $15 \mathrm{~m}$ a.g.l., however, the wind speed at the RIM tower is lower than at the NEAR tower on average, with the flow deceleration already noticed in the case study of Whiteman et al. (2018a). Figure 3a shows the wind speeds at the first levels at the NEAR and RIM towers for the night studied by Whiteman et al. (2018b), that is, at 3 and $5 \mathrm{~m}$ a.g.1., respectively. Close to the surface, the wind speed remains nearly constant between the upstream site and the crater rim, in agreement with the mean profiles in Fig. 6c, d. In contrast, a mean flow acceleration occurs throughout the entire flow depth from the NEAR tower to the RIM tower during flow-separation cases (Fig. 6a, b). This flow acceleration can also be seen in the two case studies with a small and a large wake in Fig. 3d, g. In the latter, an increase in flow speed of about 2-3 $\mathrm{m} \mathrm{s}^{-1}$ occurs near the surface throughout most of the night. 

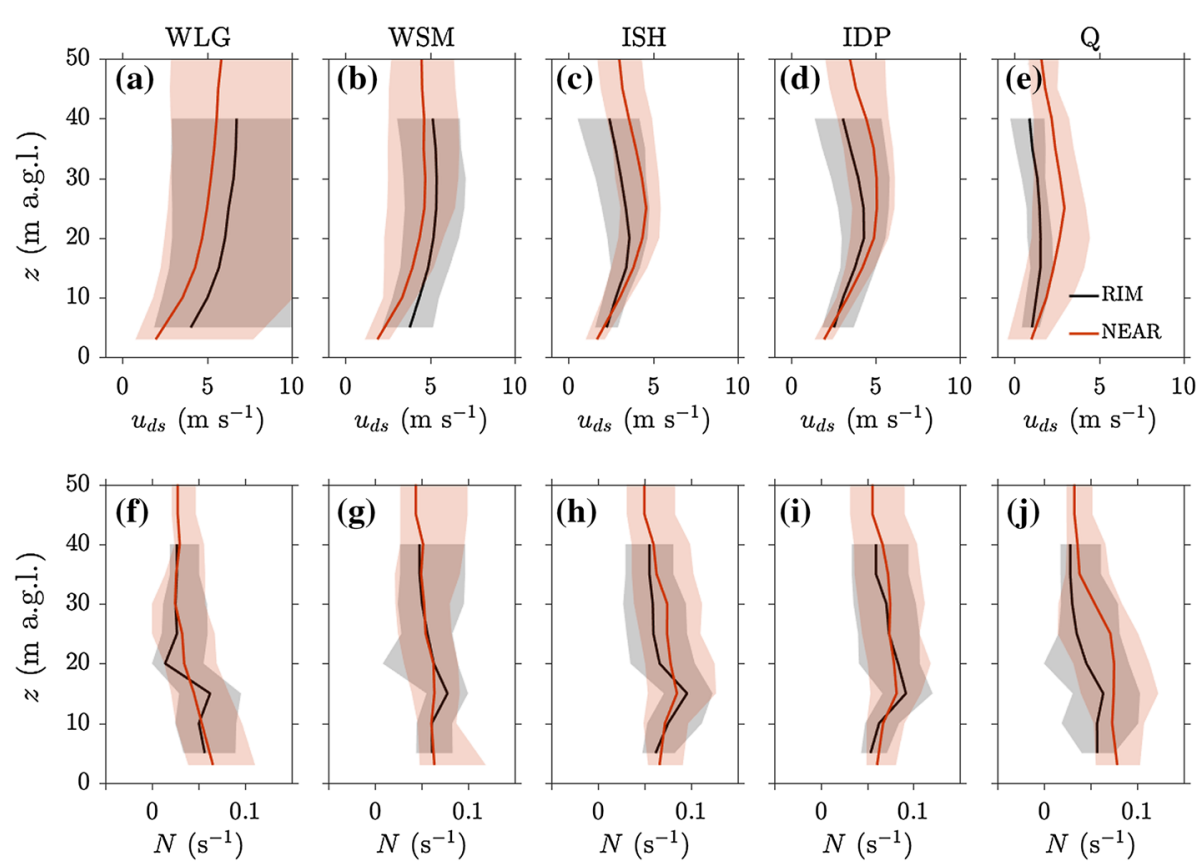

Fig. 6 Profiles of the $\mathbf{a}-\mathbf{e}$ downslope wind component and $\mathbf{f}-\mathbf{j}$ Brunt-Väisälä frequency at the NEAR tower (red) and the RIM tower (black) for the five different flow regimes. Profiles are median values and the shading indicates the 10th and 90th percentiles. The downslope wind component $u_{d s}$ was calculated in the direction of the main topographic gradient of the upstream plain, that is, $215^{\circ}$

During the night of 16-17 October (Fig. 3d), flow separation is briefly interrupted around $0200 \mathrm{MST}$ and then finally ends in the morning around 0430 MST. As mentioned before, these periods correspond to a decrease in wind speed at the RIM tower, which, however, is not reflected in the upstream near-surface wind at the NEAR tower, thus resulting in a reduced flow acceleration. Similarly, a brief drop in wind speed at the RIM tower and thus in the flow acceleration upstream occurred during the night of 27-28 October (Fig. 3g) around 0100 MST together with a decrease in wind speed at the FLR site and with the development of a basin-floor inversion. As wind speeds remain low at both the SSW2 and the SSW4 sites during this time, flow separation is still occurring but only a smaller wake forms.

To gain further insight into the flow acceleration or deceleration between the NEAR tower and the RIM tower, the pressure gradient was examined between the two sites. For the determination of the horizontal pressure difference, the pressure at the NEAR tower was extrapolated to the elevation of the pressure measurement at the RIM tower by integrating the hydrostatic equation using the temperature profile at the NEAR tower. The pressure difference between the RIM tower and the NEAR tower is positive throughout the entire night of 2627 October (Fig. 3c), that is, the pressure gradient opposes the south-westerly katabatic flow, consistent with the observed flow deceleration. During the nights of 16-17 October (Fig. 3f) and 27-28 October (Fig. 3i), on the other hand, the pressure difference is generally closer to zero or even negative. Times with a positive pressure difference match times with lower wind speeds at the RIM tower and thus a break in flow separation. Figure 7 shows the upstream change in the layer-averaged wind speed between the NEAR tower and the RIM tower together with the pressure difference between the two sites for all individual 5-min intervals. Flow separation, particularly large wakes affecting the entire south-west sidewall, 
Fig. 7 Pressure difference between the RIM tower and the NEAR tower against mean-wind-speed difference between the RIM tower and the NEAR tower

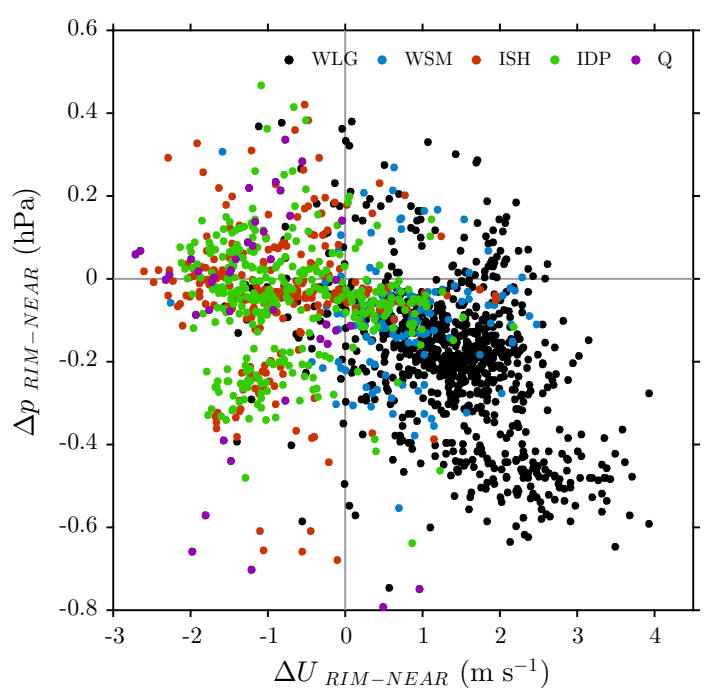

occurs mostly in the lower-right quadrant, where $\Delta p<0$ and $\Delta U>0$. This means that flow separation occurs when the pressure decreases towards the rim and the flow accelerates towards the rim. In contrast, flow intrusions occur generally with a flow deceleration. The sign of the pressure gradient, however, is independent of direction.

\section{Conditions Within the Wake Region}

When flow separation occurs at the south-west crater rim, a wake forms over the inner southwest sidewall, whose size depends on the flow conditions. The wake is characterized by low wind speeds and sometimes a return circulation near the surface, that is, an upslope flow component (see Sect. 3). In this section, we will further analyze the conditions within the wake region, including its turbulence characteristics, stability, and pressure. Time series of potential temperature along the line of temperature data-loggers running up the south-south-west sidewall and time series of pressure deviations at several sites along the south-west sidewall are shown in Fig. 8 for the three case studies. The potential-temperature time series from the south-south-west crater sidewall are overall very similar to the potential temperature time series from the north-east sidewall shown in Fig. 3, that is, they also show the development of the nocturnal crater inversion, which is disturbed during flow-separation events. In contrast to the north-east sidewall, however, the potential temperatures at the crater rim (indicated by the dark red lines in Fig. 8) are generally not the highest, but rather slightly lower than the potential temperatures in the upper part of the crater atmosphere. This slightly superadiabatic pseudo-vertical profile along the south-south-west sidewall has already been described by Whiteman et al. (2018a) for the intrusion case of the 26-27 October (Fig. 8a), who hypothesized that it is due to turbulent mixing at the bottom of the shallow cold-air-intrusion layer. During the night of 16-17 October the superadiabatic layer is even more pronounced, particularly during the first part of the night before the onset of flow separation (Fig. 8c). During the first wake formation around 0100 MST, the superadiabatic stratification is strongly reduced and the overall pseudo-vertical temperature gradient becomes close to neutral. Interestingly, the crater-floor temperature becomes even higher than the rim temperature when the crater 

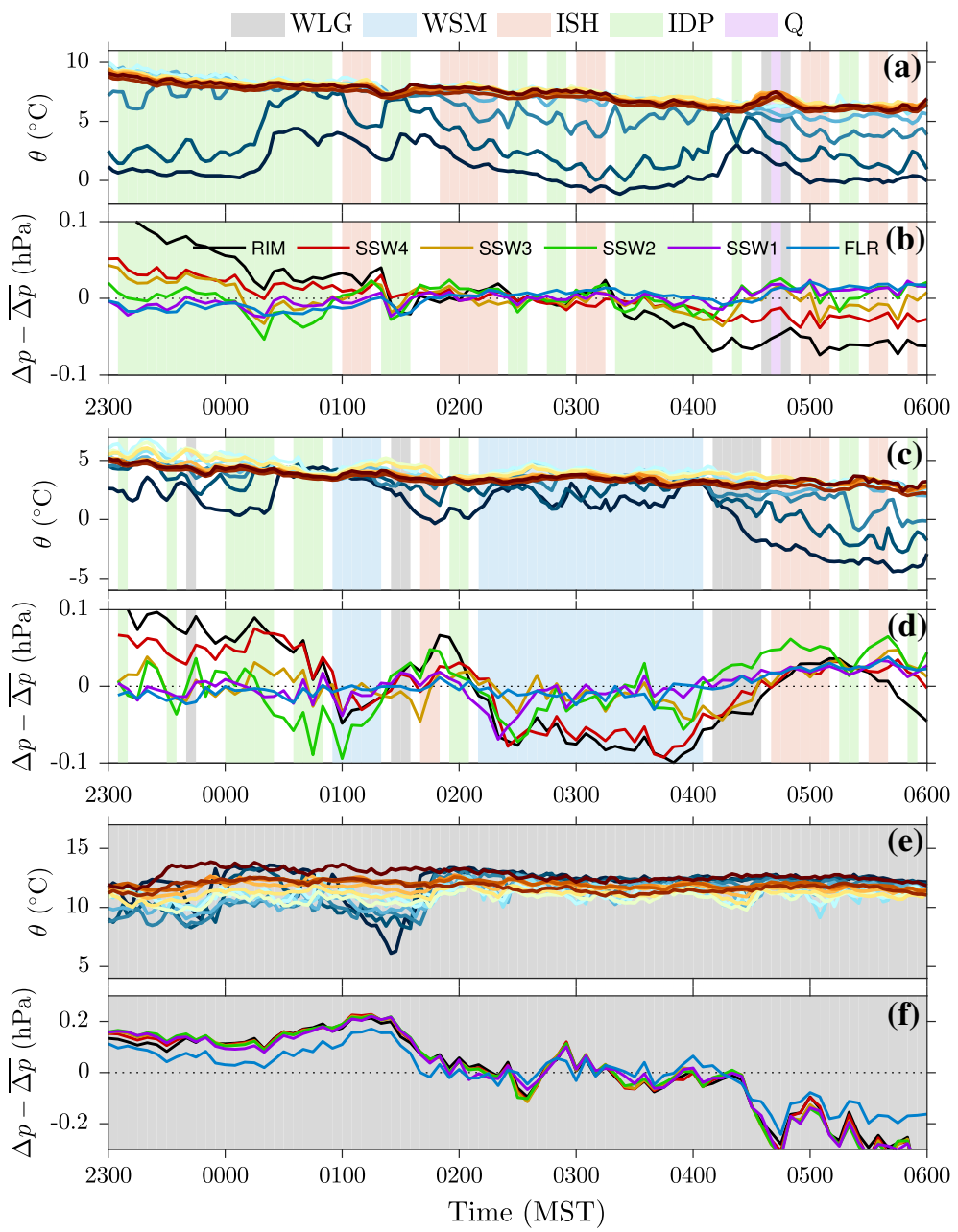

Fig. 8 Time series of $\mathbf{a}, \mathbf{c}$, e potential temperature at different sites running up the south-south-west line of temperature data-loggers from the crater floor (dark blue) to the rim (dark red) at 10-20 m height intervals and $\mathbf{b}, \mathbf{d}, \mathbf{f}$ pressure differences between sites along the south-west sidewall and a site on the opposite north-northeast sidewall on a, b 26-27, $\mathbf{c}, \mathbf{d}$ 16-17, and e, f 27-28 October. The respective mean pressure difference $\overline{\Delta p}$ over the 7-h period between 2300 and 0600 MST was subtracted from each pressure time series for better comparability among the sites. Data from the temperature data-loggers are 2.5 -min instantaneous values

inversion is destroyed by the formation of the wake - that is, a superadiabatic stratification develops in the lower part of the crater. This behaviour is particularly pronounced during the night of 27-28 October, when the crater-floor temperature becomes as high as the rim temperature and about $2-3{ }^{\circ} \mathrm{C}$ higher than the temperatures along the south-south-west sidewall (Fig. 8e).

Median pseudo-vertical potential-temperature profiles (Fig. 9a) along the south-west crater sidewall show that the superadiabatic stratification is also present on average during flow intrusions and during the formation of small wakes, with the small-wake cases on average colder than the intrusion cases. For completely quiescent cases, the temperature profile is close to the nocturnal temperature profile observed in other small basins under undisturbed 

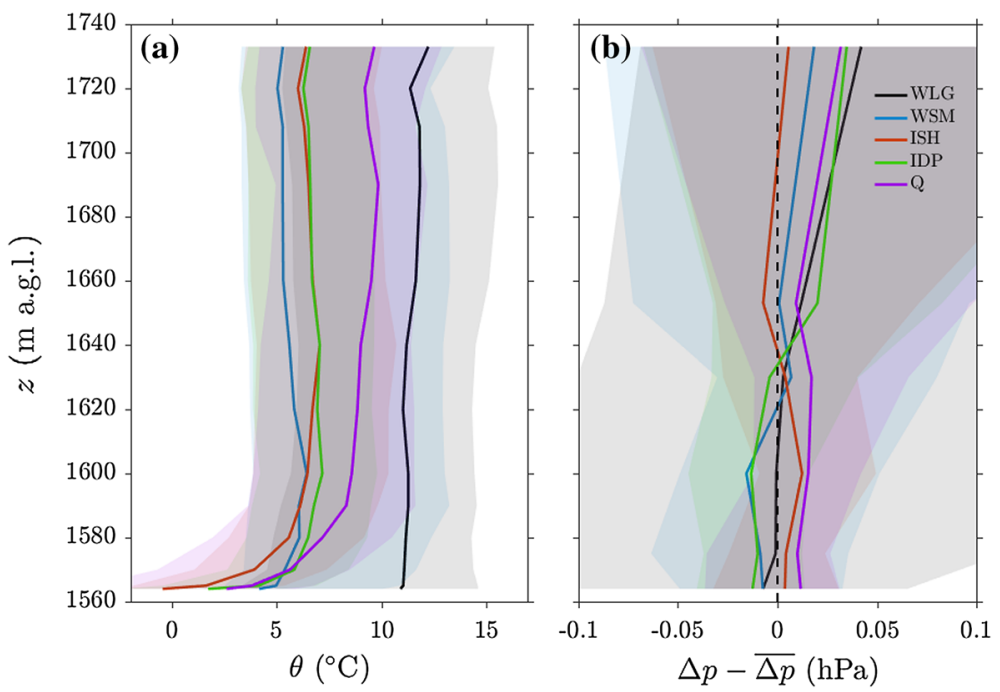

Fig. 9 Pseudo-vertical profiles of median, a potential temperature, and $\mathbf{b}$ pressure deviations along the southsouth-west crater sidewall for the different flow regimes. Pressure deviations were calculated with respect to a reference site on the north-east sidewall and the mean over the period 2300-0600 MST was subtracted for better comparability among the sites. Shading indicates the 10th and 90th percentiles

conditions (Clements et al. 2003; Whiteman et al. 2004; Dorninger et al. 2011), with a continuously stably stratified layer to the top of the crater basin. Large wakes result on average in a well-mixed and warmer crater atmosphere, likely due to the presence of strong winds at the RIM tower.

Pressure deviations on the south-west sidewall were calculated with respect to the NNE site on the relatively undisturbed north-east sidewall. To increase the comparability among the individual sites by removing the altitude effect, the mean pressure difference between each site and the NNE site between 2300 and 0600 MST was subtracted from the respective time series. With the exception of a weak diurnal trend, particularly at the RIM tower, the pressure remains relatively constant throughout the night of 26-27 October, when no wakes form over the south-west sidewall (Fig. 8b). During the night of 16-17 October, the pressure along the south-west sidewall is affected by the formation, breakup, and subsequent reformation of the small wake (Fig. 8d). The pressure at the RIM tower, the SSW4 site, and the SSW2 site drops with the formation of a wake around midnight, increases to a positive peak during the short breakup of the wake around $0200 \mathrm{MST}$ and then decreases again. It remains low until about $0400 \mathrm{MST}$ at the RIM tower and the SSW4 site, although the pressure increases already somewhat earlier at the SSW2 site. Even at the SSW1 site farther down the slope, a short drop in pressure is observed after 0200 MST. Interestingly, the SSW3 site, which is located between the SSW4 and SSW2 sites, remains unaffected. Even during the night of 27-28 October, the brief weakening of the wake around 0100 MST, which is indicated by a stabilization of the crater atmosphere, leads to a brief increase in pressure at all sites (Fig. 8f). Average pressure-perturbation profiles (Fig. 9b) suggest that during quiescent conditions and shallow intrusions the pressure is on average higher over the south-west sidewall than over the opposing north-east sidewall in the lower part of the crater, whereas during deeper intrusions and small wakes the pressure gradient reverses. During large wakes, the pressure distribution is relatively homogeneous. In the upper part of the crater, the pressure over the south-west sidewall is generally higher than over the north-east sidewall independent of the flow regime. 
It has to be kept in mind, however, that only one reference site, located in the lower part of the crater, exists on the north-east sidewall.

Turbulence characteristics in the wake region, such as turbulence kinetic energy (TKE), the velocity-aspect ratio (Vickers and Mahrt 2006)

$$
V A R=\left(\frac{2 \overline{w^{\prime 2}}}{\overline{u^{\prime 2}}+\overline{v^{\prime 2}}}\right)^{1 / 2},
$$

momentum fluxes, and the vertical heat flux are shown for the three case studies in Fig. 10 and for the entire month in Fig. 11. In the absence of a wake over the south-west sidewall during the night of 26-27 October, TKE is generally low with the exception of the SSW2 site (Fig. 10a), which is located near the top of the basin-floor inversion and most of the time at the lower edge of cold-air inflow (Fig. 3a). Turbulence kinetic energy at the SSW2 site is dominated by contributions from the horizontal velocity variances $\overline{u^{\prime 2}}$ and $\overline{v^{\prime 2}}$. While TKE is generally weak at the other sites, VAR values are closer to 1 at the RIM tower and to a lesser degree at the SSW4 site, meaning that $\overline{w^{\prime 2}}$ has a similar magnitude as $\overline{u^{\prime 2}}$ and $\overline{v^{\prime 2}}$ and turbulence is closer to isotropic. During the night of 16-17 October, TKE at the SSW4 site reaches values similar to the SSW2 site (Fig. 10e). This increase in TKE compared to the night of 26-27 October is due to an increase in the variances of all three velocity components, but particularly after $0200 \mathrm{MST}, \overline{u^{\prime 2}}$ and $\overline{v^{\prime 2}}$ increase more strongly than $\overline{w^{\prime 2}}$, leading to a decrease in VAR. Turbulence kinetic energy increases strongly at the basin floor and at the crater rim when a large wake forms during the night of 27-28 October, with comparatively low values along the south-west sidewall (Fig. 10i). The VAR values also remain relatively low during this night (Fig. 10j).

The generally low values of TKE at the RIM and FLR sites, with the exception of large wakes when particularly $\overline{u^{\prime 2}}+\overline{v^{\prime 2}}$ increases significantly, can be observed throughout the entire month (Fig. 11a, d). On the other hand, large wakes are generally characterized by low TKE at both the SSW2 and the SSW4 site (Fig. 11b, c). For small wakes, the increase in TKE at the SSW2 site observed during the night of 16-17 October is also seen throughout the month (Fig. 11c). At the SSW4 site, however, the small wakes show relatively large scatter of both $\overline{w^{\prime 2}}$ and $\overline{u^{\prime 2}}+\overline{v^{\prime 2}}$ (Fig 11b). For intrusions, the analysis of the entire month shows a slightly different picture than just the night of 26-27 October. It can be clearly seen that at the SSW4 site, TKE is generally higher during intrusions than during wake events, with an increase in both $\overline{w^{\prime 2}}$ and $\overline{u^{\prime 2}}+\overline{v^{\prime 2}}$. Similarly, larger TKE values occur at the SSW2 site during deep-intrusion events, when the cold-air intrusions actually reach the site, with relatively large scatter during the less deep intrusion events (Fig 11c). In contrast to the SSW4 site, however, the increase in TKE at the SSW2 site is generally due to an increase in $\overline{u^{\prime 2}}+\overline{v^{\prime 2}}$, while $\overline{w^{\prime 2}}$ remains low.

The momentum fluxes are also influenced by the formation of a wake over the south-west sidewall. The streamwise momentum flux $\overline{u^{\prime} w^{\prime}}$ is generally positive at the SSW4 and SSW2 sites during both the night of 26-27 October (intrusions; Fig. 10c) and the night of 1617 October (small wake; Fig. 10g), with negligible values at the RIM tower and at the FLR site. As a small wake forms during the night of $16-17$ October, $\overline{u^{\prime} w^{\prime}}$ increases at the SSW2 site compared to the intrusion night of 26-27 October, with a weak minimum between 0100 and 0200 MST together with the brief breakup of the wake. The lateral momentum flux $\overline{v^{\prime} w^{\prime}}$ increases as well (not shown), but remains small compared to the streamwise component. Based on the wind speed, it had been established that small wakes do not affect the SSW2 site but only the SSW4 site farther up the slope. The close correlation between the momentum 

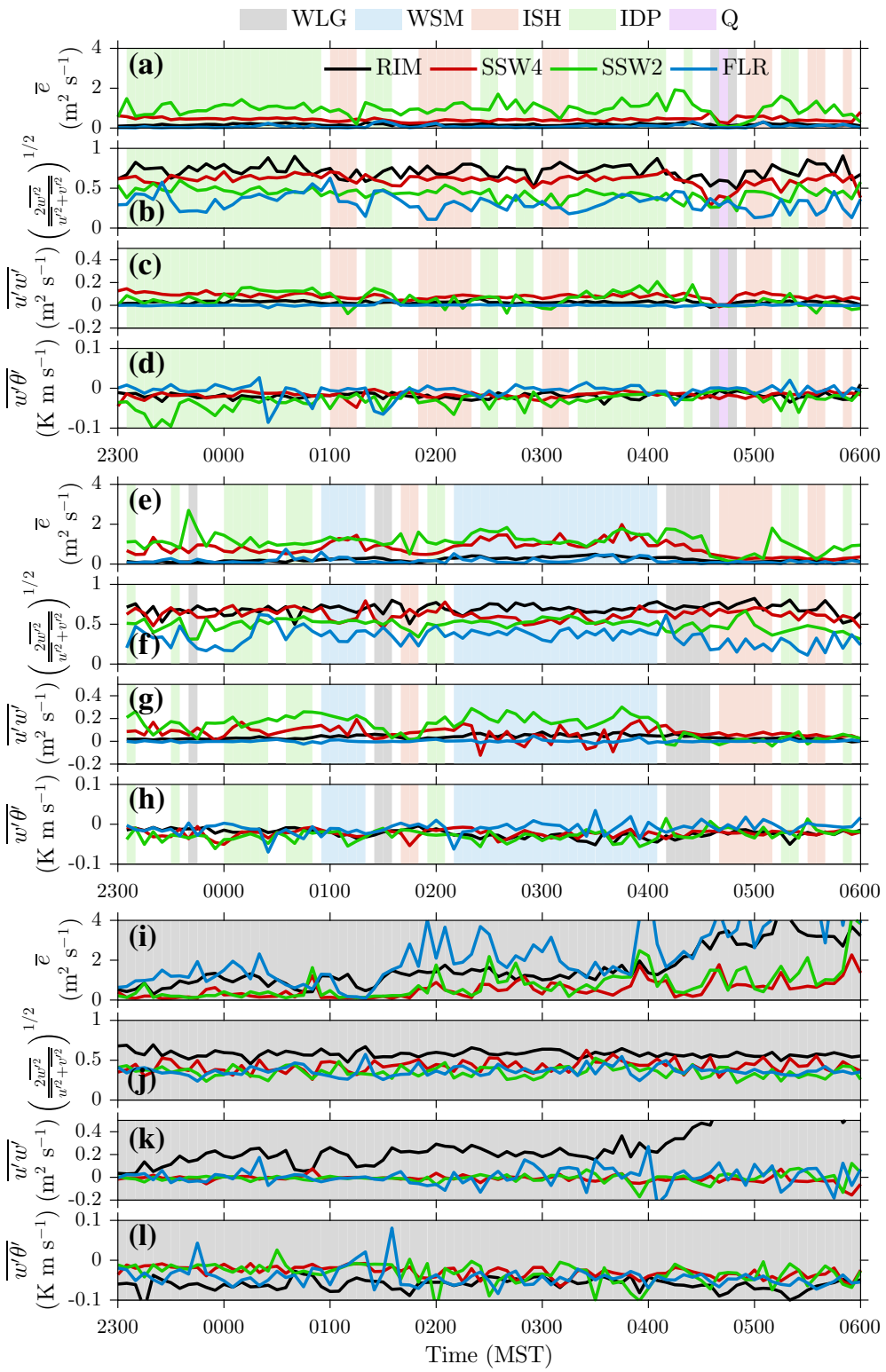

Fig. 10 Time series of $\mathbf{a}, \mathbf{e}, \mathbf{i}$ TKE, $\mathbf{b}, \mathbf{f}, \mathbf{j}$ the velocity-aspect ratio, $\mathbf{c}, \mathbf{g}, \mathbf{k}$ the streamwise momentum flux, and $\mathbf{d}, \mathbf{h}, \mathbf{l}$ the vertical heat flux on $\mathbf{a}-\mathbf{d}$ 26-27, e-h 16-17, and $\mathbf{i}-\mathbf{l}$ 27-28 October

flux at the SSW2 site and the timing of the wake, however, suggests that the SSW2 site is affected, even though the wake does not extend this far down the sidewall. This may be related to another phenomenon, that is, the formation of gravity waves and associated warmair intrusions (Whiteman et al. 2018b), which form under similar conditions to small wakes. This will be further discussed in Sect. 6 .

The increase in momentum flux at the SSW2 site for small wakes can also be seen throughout the month, but with relatively large scatter (Fig. 11g). Increased values in $\overline{u^{\prime} w^{\prime}}$ result also 

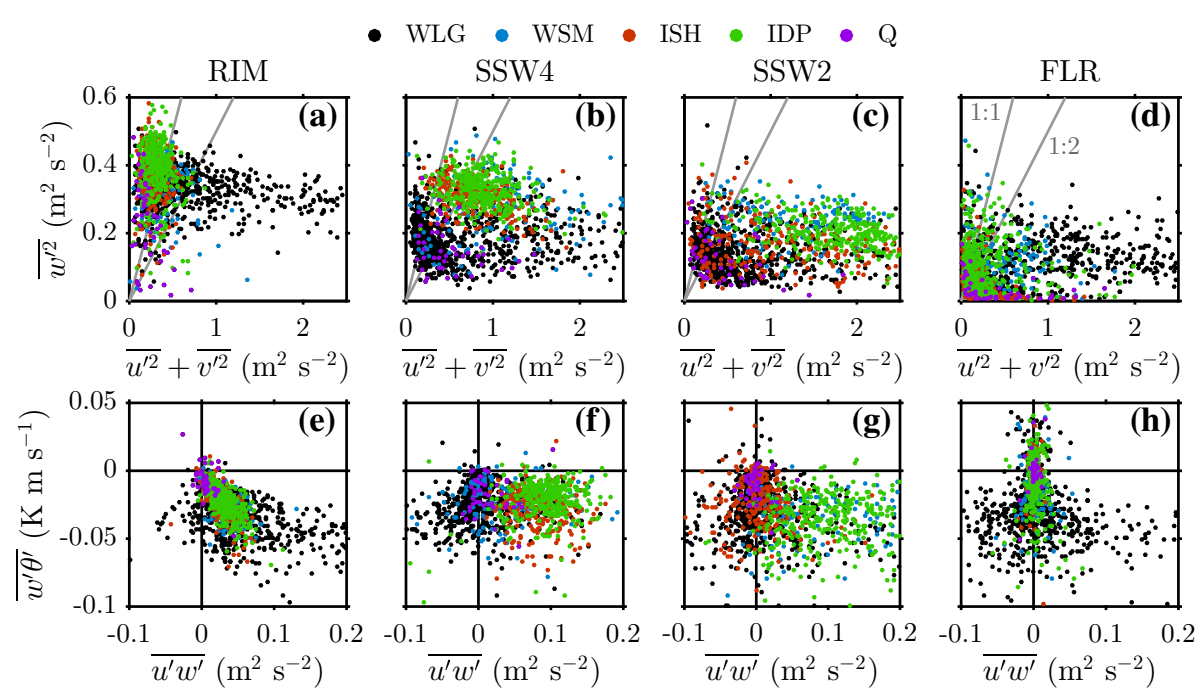

Fig. 11 a-d Contributions of $\overline{u^{\prime 2}}+\overline{v^{\prime 2}}$ and $\overline{w^{\prime 2}}$ to TKE and $\mathbf{e}-\mathbf{h}$ vertical heat flux and streamwise momentum flux at a, e the RIM tower and the b, f SSW4, $\mathbf{c}, \mathbf{g}$ SSW2, and $\mathbf{d}, \mathbf{h}$ FLR sites

from deep intrusions reaching the lower sidewall. At the SSW4 site, positive values of momentum flux are observed during all intrusions and close to zero or negative values during wakes (Fig. 11f). The generally positive values during intrusions suggest that the cold-air intrusions are extremely shallow, with the highest wind speeds located below the measurement height of $3 \mathrm{~m}$ a.g.l., resulting in an upward momentum transport.

During large wakes (e.g., 27-28 October, Fig. 10h) the momentum fluxes at the RIM tower and sometimes at the FLR site increase in magnitude, with relatively low values at the other sites (Fig. 11e-h). However, while the momentum flux at the RIM tower remains positive, negative values are equally possible at the FLR site.

In the vertical heat flux, there is little difference between intrusions and wakes. It is overall negative at all sites, consistent with stable conditions, with values close to zero during intrusions and small wakes (Figs. 10b, d and 11e-h). Some small positive values are possible at the FLR site (Fig. 11h). The magnitude of the heat flux is generally independent of the flow regime (Fig. 11e-h). During the night of 27-28 October, however, when a large wake forms, the heat flux increases in magnitude at all sites despite the almost neutral stratification during this time (Fig. 101).

Scintillometer measurements were made across the south-west part of the crater to observe turbulence intensity in the immediate lee of the rim, where the flow separates from the surface. The scintillometer path is indicated by the orange line in Fig. 1. A time series of the refractive-index structure parameter $C_{n}^{2}$ is shown in Fig. 12 for the night of 1617 October. $C_{n}^{2}$ is a measure for the spatial variability of the refractive index of air and thus for turbulence intensity. During this night, $C_{n}^{2}$ increased around $0200 \mathrm{MST}$ together with the onset of flow separation, indicating increased turbulence intensities near the top of the crater compared to time periods with flow intrusions. A similar, although much weaker, increase was also observed during the shorter period of flow separation around 0100 MST. A statistical comparison of $C_{n}^{2}$ for the five different flow categories for the whole month revealed, however, similar median values for small wakes and the two intrusion categories and even a lower 75 percentile value for small wakes (not shown). Large wakes, on the other 


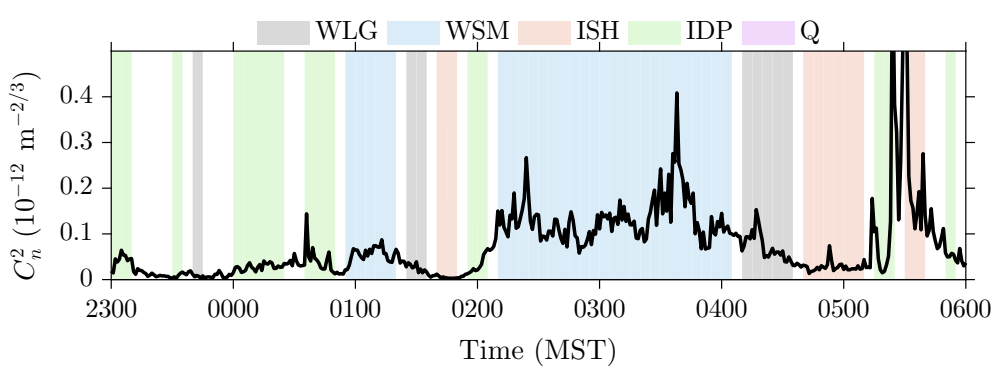

Fig. 12 Time series of the refractive index structure parameter on 16-17 October, averaged over 1-min intervals

hand, have a slightly higher median value and a much larger 75 percentile. It is conceivable that the small wakes were oftentimes too shallow to be captured by the scintillometer path. The available measurements during METCRAX II, however, did not allow for a determination of the actual slope-normal wake depth.

\section{Summary and Conclusions}

Observations have been presented from the METCRAX II field campaign in the approximately 170-m deep and 1.2-km wide Meteor Crater in Arizona that show that wakes form above the inner south-west crater sidewall. The Meteor Crater is located on an extensive plain that slopes slightly upwards to the south-west, so that a south-westerly katabatic flow forms in connection with a surface-based inversion during quiescent and undisturbed nights. As the south-westerly katabatic wind flows over the approximately 30-50-m high crater rim, the flow either runs down the south-west sidewall because the air is colder than the ambient crater atmosphere or it separates from the surface, forming a wake over the inner sidewall.

The analysis focused on night-time data from the one-month long measurement campaign. The data were classified into five regimes based on wind-speed observations at the southwest crater rim and at two sites on the south-west inner sidewall: flow separation with the formation of either (i) large wakes that affect the entire south-west sidewall (WLG) or (ii) small wakes that affect only the upper part of the south-west sidewall (WSM), (iii) deep and (iv) shallow cold-air intrusions when no wake forms but part of the upstream drainage flow runs down the sidewall until it reaches its level of neutral buoyancy (IDP and ISH), and finally, (v) quiescent conditions (Q). Schematic diagrams of the two wake regimes and the two intrusion regimes in Fig. 13 summarize the findings. The classification scheme is of course strongly site dependent. For example, if very small wakes form over the upper part of the crater sidewall that do not extend to the SSW4 site, they are classified as intrusion regimes. Similarly, the classification into deep versus shallow intrusions and large versus small wakes is based on wind-speed observations at the SSW2 site, a site approximately $50 \mathrm{~m}$ above the crater floor. Observations at a lower or higher site may lead to different classifications. A thorough analysis of a cold-air-intrusion-dominated night is presented by Whiteman et al. (2018a), who also showed that cold-air intrusions (Fig. 13a, b) form when the upstream katabatic flow is shallow according to the classification by Stiperski et al. (2018) and the flow decelerates towards the crater. As the lower part of the drainage flow is colder than the crater atmosphere, the cold air runs down the sidewall until it reaches its level of neutral buoyancy. The location of the level of neutral buoyancy determines whether shallow (Fig. 13a) or deep (Fig. 13b) intrusions form, that is, whether the intrusion reaches to the SSW2 site. The crater 

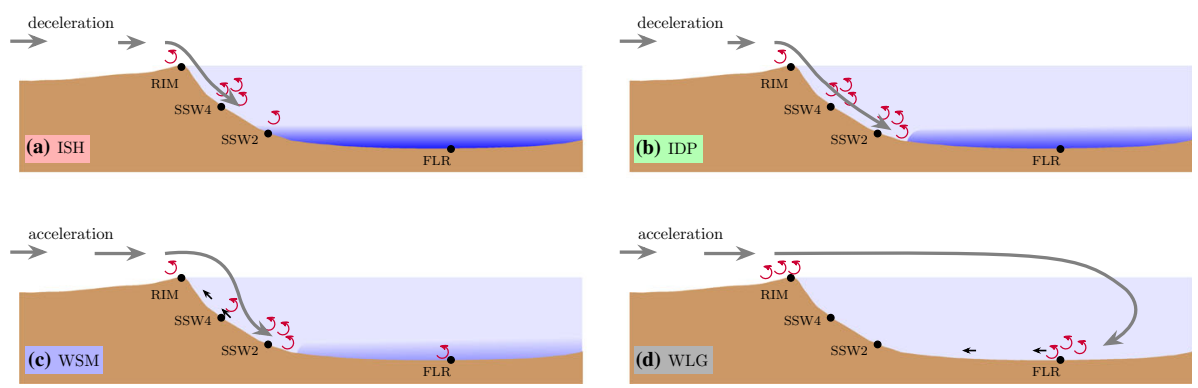

Fig. 13 Schematic diagrams of a shallow intrusions, b deep intrusions, c small wakes, and d large wakes. Grey arrows indicate the major flow characteristics. Small black arrows show potential recirculation zones and small red eddies indicate turbulence intensity, with a larger number of eddies indicating higher TKE. The gradient in the blue shading reflects the vertical temperature gradient

atmosphere is typically strongly stratified in the lowest layer during intrusions, but relatively high turbulence intensities are observed in the vicinity of the intrusion flow. While the lower part of the south-west sidewall is thus typically characterized by quiescent conditions for shallow intrusions, wind speed and turbulence intensities increase and stability decreases for deep intrusions.

A fifth, quiescent regime was defined to filter out data with overall low wind speeds at the crater rim and along the south-west crater sidewall. Based on our classification method, these data would have otherwise not been distinguishable from the flow-separation regimes, which, however, form only under higher wind speeds. The general conditions both upstream (e.g., wind speed and profiles) and in the crater (e.g., stability) during these quiescent periods are very similar to intrusions. This category is thus not a separate physical regime, but rather consists of intrusions under very weak wind conditions.

The occurrence of flow separation and subsequent wake formation generally matches the criterion for bluff-body flow separation by Baines (1995), that is, that the leeside half-length of the obstacle is smaller than the half wavelength of the internal waves excited by the obstacle. Estimating the half-length of the crater sidewall, the resulting criterion becomes $N / U<0.02 \mathrm{~m}^{-1}$ for the Meteor Crater, that is, flow separation is facilitated by lower stability and higher wind speeds. Wind speed at the crater rim plays a crucial role, with flow separation becoming the dominant regime for layer-averaged wind speeds $>5 \mathrm{~m} \mathrm{~s}^{-1}$. The upstream wind profile in flow-separation conditions is typically characterized by a deep katabatic flow, according to the classification by Stiperski et al. (2018), and the flow accelerates towards the crater, with the horizontal pressure gradient just upwind of the crater rim opposing the direction of the katabatic flow (Fig. 13c, d).

Flow separation leading to the formation of small wakes is summarized in Fig. 13c, with the slope-normal extent of the wake probably exaggerated. Lidar scans were performed from a site slightly below the SSW2 site, but the small wakes seem to be too small to be seen by the lidar scans. For small wakes, the upper part of the sidewall is characterized by low wind speeds and low turbulence intensities compared to the lower sidewall. While the wake does not extend to the lower sidewall, conditions at the lower sidewall and at the crater floor still show some correlation with the formation of the wake, for example, increased wind speeds and momentum fluxes and reduced stability. The conditions leading to flow separation and small wakes are, however, similar to the conditions leading to the formation of deep gravity waves over the crater and the associated downward transport of warm air into the crater from above (Whiteman et al. 2018b). The night analyzed by Whiteman et al. (2018b) (IOP4; 19- 
20 October) is overall very similar to the night of 16-17 October, that is, our case study for small-wake formation. This suggests that small wakes may occur together with a deep wave downstream, which causes the increased wind speeds at the SSW2 site and the increased mixing and destabilization in the lower part of the crater. An open question is whether the reduced stability in the crater as a result of the gravity waves facilitates flow separation at the rim. Whiteman et al. (2018b) also identified a transitional period when the flow over the crater rim bifurcates leading to a quiescent, wake-like flow region between the two bifurcating flow layers over the south-west part of the crater, which they called a cavity. This cavity, however, is not identical with the wake identified here, which forms below the intruding flow (Fig. 13c), whereas the cavity is located above the intruding branch of the flow (see their Fig. 11).

With very high wind speeds upstream $\left(\gtrsim 7 \mathrm{~m} \mathrm{~s}^{-1}\right)$ only large wakes form, whereas for lower wind speeds either small or large wakes form. A schematic diagram of this regime is presented in Fig. 13d. Since no IOP was conducted during persistent large-wake conditions, direct observations of the large, crater-size eddy indicated in Fig. $13 \mathrm{~d}$ are not available and it is possible that deep waves discussed in Whiteman et al. (2018b) are also present in this regime. Observations from the crater floor, however, show a return circulation that opposes the south-westerly flow above the crater and pseudo-vertical temperature profiles along the crater sidewalls indicate a well-mixed crater atmosphere. Similar conditions representative of our large wake cases were simulated by Katurji et al. (2013), who performed idealized simulations of flow over a basin with a size similar to the Meteor Crater, with wind speeds of $10 \mathrm{~m} \mathrm{~s}^{-1}$ and neutral stratification.

The observation of flow separation at the crater rim yielded another detail in the understanding of the complex nocturnal flow at the Meteor Crater and the different flow regimes resulting from the interaction of the south-westerly katabatic flow with the crater topography. While the available observations did not allow a direct visualization or determination of the exact wake size, the data provided a detailed description of the flow characteristics within and downstream of the wake and allowed the analysis of the conditions leading to flow separation at the crater rim. These data may thus serve as a test bed for numerical modeling studies of flow past topography in that the topography and the upstream atmospheric conditions leading to both flow separation and attached flow are well known. Numerical simulations, on the other hand, may be necessary to generalize the results and extend them to other topographic and flow conditions and to learn more about the spatial extent of the wake.

Acknowledgements Open access funding provided by University of Innsbruck and Medical University of Innsbruck. This research was supported by the National Science Foundation's Physical and Dynamic Meteorology Division through Grant AGS-1160730. The contributions from KIT were funded by the International Bureau of BMBF under Grant 01 DM 13002. We thank the many METCRAX II collaborators and volunteers helping in the field, the property owners for field access, and the colleagues who provided additional equipment, who are all listed as either coauthors or in the acknowledgment section of Lehner et al. (2016b). We also appreciate the time and effort of two reviewers, whose comments helped to improve the manuscript.

Open Access This article is distributed under the terms of the Creative Commons Attribution 4.0 International License (http://creativecommons.org/licenses/by/4.0/), which permits unrestricted use, distribution, and reproduction in any medium, provided you give appropriate credit to the original author(s) and the source, provide a link to the Creative Commons license, and indicate if changes were made.

\section{References}

Adler B, Whiteman CD, Hoch SW, Lehner M, Kalthoff N (2012) Warm-air intrusions in Arizona's Meteor Crater. J Appl Meteorol Clim 51:1010-1025

Ambaum MHP, Marshall DP (2005) The effects of stratification on flow separation. J Atmos Sci 62:2618-2625 
Arya SPS, Capuano ME, Fagen LC (1987) Some fluid modeling studies of flow and dispersion over twodimensional low hills. Atmos Environ 21:753-764

Baines PG (1995) Topographic effects in stratified flow. Cambridge University Press, Cambridge

Baines PG, Hoinka KP (1985) Stratified flow over two-dimensional topography in fluid of infinite depth: a laboratory simulation. J Atmos Sci 42:1614-1630

Batchelor GK (1967) An introduction to fluid dynamics. Cambridge University Press, Cambridge

Belcher SE, Hunt JCR (1998) Turbulent flow over hills and waves. Ann Rev Fluid Mech 30:507-538

Clements CB, Whiteman CD, Horel JD (2003) Cold-air pool structure and evolution in a mountain basin: Peter Sinks, Utah. J Appl Meteorol 42:752-768

Dorninger M, Whiteman CD, Bica B, Eisenbach S, Pospichal B, Steinacker R (2011) Meteorological events affecting cold-air pools in a small basin. J Appl Meteorol Clim 50:2223-2234

Doyle JD, Durran DR (2002) The dynamics of mountain-wave induced rotors. J Atmos Sci 59:186-201

Doyle JD, Durran DR (2007) Rotor and subrotor dynamics in the lee of three-dimensional terrain. J Atmos Sci 64:4202-4221

French JF, Haimov SJ, Oolman LD, Grubišić V, Serafin S, Strauss L (2015) Wave-induced boundary layer separation in the lee of the Medicine Bow Mountains. Part I: observations. J Atmos Sci 72:4845-4863

Gerber F, Lehning M, Hoch SW, Mott R (2017) A close-ridge small-scale atmospheric flow field and its influence on snow accumulation. J Geophys Res Atmos 122:7737-7754

Grubišić V, Doyle JD (2006) Terrain-induced rotor experiment. In: 12th conference on mountain meteorology, American Meteorological Society, Santa Fe, New Mexico, USA

Haiden T, Whiteman CD, Hoch SW, Lehner M (2011) A mass flux model of nocturnal cold-air intrusions into a closed basin. J Appl Meteor Clim 50:933-943

Hertenstein RF, Kuettner JP (2005) Rotor types associated with steep lee topography: influence of the wind profile. Tellus 57A:117-135

Holden JJ, Derbyshire SH, Belcher SE (2000) Tethered balloon observations of the nocturnal stable boundary layer in a valley. Boundary-Layer Meteorol 97:1-24

Jackson PL, Mayr G, Vosper S (2012) Dynamically-driven winds. Mountain weather research and forecasting. Springer, Berlin, pp 121-218

Katurji M, Zhong S, Kiefer M, Zawar-Reza P (2013) Numerical simulations of turbulent flow within and in the wake of a small basin. J Geophys Res 118:6052-6063

Kim J-J, Baik J-J, Chun H-Y (2001) Two-dimensional numerical modeling of flow and dispersion in the presence of hill and buildings. J Wind Eng Ind Aerodyn 89:947-966

Lehner M, Rotunno R, Whiteman CD (2016a) Flow regimes over a basin induced by upstream katabatic flows - an idealized modeling study. J Atmos Sci 73:3821-3842

Lehner M, Whiteman CD, Hoch SW, Crosman ET, Jeglum ME, Cherukuru NW, Calhoun R, Adler B, Kalthoff N, Rotunno R, Horst TW, Semmer S, Brown WOJ, Oncley SP, Vogt R, Grudzielanek AM, Cermak J, Fonteyne NJ, Bernhofer C, Pitacco A, Klein P (2016b) The METCRAX II field experiment—a study of downslope windstorm-type flows in Arizona's Meteor Crater. Bull Am Meteorol Soc 97:217-235

Mahrt L, Sun J, Blumen W, Delany T, Oncley S (1998) Nocturnal boundary-layer regimes. Boundary-Layer Meteorol. 88:255-278

Mason PJ (1987) Diurnal variations in flow over a succession of ridges and valleys. Q J R Meteorol Soc 113:117-1140

Menke R, Vasiljević N, Mann J, Lundquist JK (2018) Characterisation of recirculation zones in complex terrain using multi-lidar measurements. In: 18th Conference on mountain meteorology, American Meteorological Society, Santa Fe, New Mexico, USA

Patton EG, Katul GG (2009) Turbulent pressure and velocity perturbations induced by gentle hills covered with sparse and dense canopies. Boundary-Layer Meteorol 133:189-217

Poggi D, Katul GG (2007) Turbulent flows on forested hilly terrain: the recirculation region. Q J R Meteorol Soc 133:1027-1039

Rotunno R, Lehner M (2016) Two-layer stratified flow past a valley. J Atmos Sci 73:4065-4076

Scorer RS (1955) Theory of airflow over mountains: IV-Separation of flow from the surface. Q J R Meteorol Soc 81:340-350

Smolarkiewicz PK, Rotunno R (1989) Low Froude number flow past three-dimensional obstacles. Part I: baroclinically generated lee vortices. J Atmos Sci 46:1154-1164

Stiperski I, Whiteman CD, Lehner M, Holtslag AAM (2018) On the turbulence structure, dominant scales and scaling of deep katabatic flows on a shallow slope. In: EGU General Assembly 2018, Vienna, Austria

Strauss L, Serafin S, Haimov S, Grubišić V (2015) Turbulence in breaking mountain waves and atmospheric rotors estimated from airborne in situ and Doppler radar measurements. Q J R Meteorol Soc 141:32073225 
Strauss L, Serafin S, Grubišić V (2016) Atmospheric rotors and severe turbulence in a long deep valley. J Atmos Sci 73:1481-1506

van de Wiel BJH, Moene AF, Hartogensis OK, de Bruin HAR, Holtslag AAM (2003) Intermittent turbulence in the stable boundary layer over land. Part III: a classification for observations during CASES-99. J Atmos Sci 60:2509-2522

Vickers D, Mahrt L (2006) A solution for flux contamination by mesoscale motions with very weak turbulence. Boundary-Layer Meteorol 118:431-447

Voigt M, Wirth V (2013) Mechanisms of banner cloud formation. J Atmos Sci 70:3631-3640

Vosper SB (2004) Inversion effects on mountain lee waves. Q J R Meteorol Soc 130:1723-1748

Whiteman CD, Eisenbach S, Pospichal B, Steinacker R (2004) Comparison of vertical soundings and sidewall air temperature measurements in a small Alpine basin. J Appl Meteorol 43:1635-1647

Whiteman CD, Hoch SW, Lehner M, Haiden T (2010) Nocturnal cold air intrusions into a closed basin: observational evidence and conceptual model. J Appl Meteorol Clim 49:1894-1905

Whiteman CD, Lehner M, Hoch SW, Adler B, Kalthoff N, Haider T (2018a) Katabatically driven cold air intrusions into a basin atmosphere. J Appl Meteorol Clim 57:435-455

Whiteman CD, Lehner M, Hoch SW, Adler B, Kalthoff N, Vogt R, Feigenwinter I, Haiden T, Hills MOG (2018b) The nocturnal evolution of atmospheric structure in a basin as a larger-scale katabatic flow is lifted over its rim. J Appl Meteorol Clim 57:969-989

Whiteman CD, Muschinski A, Zhong S, Fritts D, Hoch SW, Hahnenberger M, Yao W, Hohreiter V, Behn M, Cheon Y, Clements CB, Horst TW, Brown WOJ, Oncley SP (2008) METCRAX 2006-Meteorological experiments in Arizona's Meteor Crater. Bull Am Meteorol Soc 89:1665-1680

Wilczak JM, Oncley SP, Stage SA (2001) Sonic anemometer tilt correction algorithms. Boundary-Layer Meteorol 99:127-150

Wirth V, Kristen M, Leschner M, Reuder J, Schween JH (2012) Banner clouds observed at Mount Zugspitze. Atmos Chem Phys 12:3611-3625

Wood N (1995) The onset of separation in neutral, turbulent flow over hills. Boundary-Layer Meteorol 76:137_ 164

Publisher's Note Springer Nature remains neutral with regard to jurisdictional claims in published maps and institutional affiliations. 